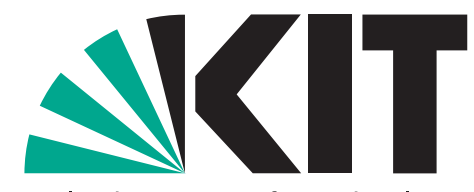

Karlsruher Institut für Technologie

\title{
Animal welfare and human ethics: A personality study
}

by Konstanze Albrecht, Florentin Krämer and Nora Szech

No. 103 | JUNE 2017

\section{WORKING PAPER SERIES IN ECONOMICS}

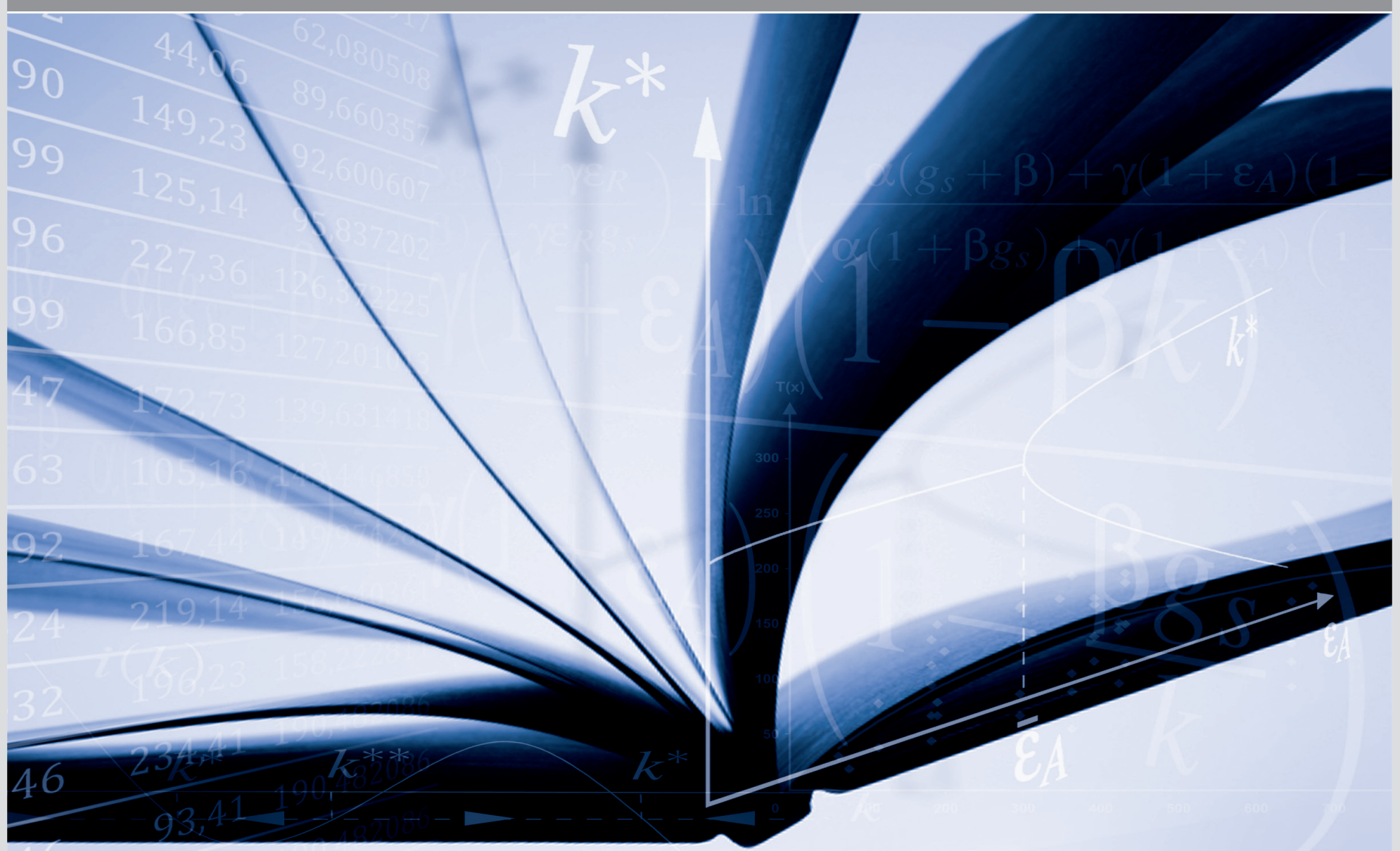




\section{Impressum}

Karlsruher Institut für Technologie (KIT)

Fakultät für Wirtschaftswissenschaften

Institut für Volkswirtschaftslehre (ECON)

Kaiserstraße 12

76131 Karlsruhe

KIT - Die Forschungsuniversität in der Helmholtz-Gemeinschaft

Working Paper Series in Economics

No. 103, June 2017

ISSN 2190-9806

econpapers.wiwi.kit.edu 


\title{
ANIMAL WELFARE AND HUMAN ETHICS: A PERSONALITY STUDY*
}

\author{
KONSTANZE ALBRECHT ${ }^{\mathrm{a}}$, FLORENTIN KR ̈̈MER ${ }^{\mathrm{b}}$, \\ and NORA SZECH ${ }^{\dagger c, d}$ \\ ${ }^{a}$ RWTH Aachen University, Institute of Psychology, Jaegerstrasse 17-19, 52062 Aachen, \\ Germany,e-mail: albrecht@psych.rwth-aachen.de \\ ${ }^{\mathrm{b}}$ University of Munich, Seminar for Economic Theory, Ludwigstrasse 28, 80539 München, \\ Germany,e-mail: florentin.kraemer@econ.lmu.de \\ ${ }^{\mathrm{c}}$ Karlsruhe Institute of Technology (KIT), Chair of Political Economics, Fritz-Erler-Strasse \\ 1-3, 76128 Karlsruhe, Germany, e-mail: nora.szech@kit.edu, phone: +49 721 608-43809 \\ ${ }^{\mathrm{d}}$ Berlin Social Science Center (WZB), Reichpietschufer 50, 10785 Berlin, Germany
}

May 22, 2017

\begin{abstract}
We elicit concern for animal welfare in an incentivized, direct and real setup that allows us to separate genuine interest in animal welfare from confounding factors like advertisement, replacement arguments or image concerns. Subjects choose between intensive farming and organic living conditions for a laying hen. Opting for better living conditions is costly, but guarantees better food, daylight, and more space to the hen. Hence subjects have to trade off a selfish benefit (money) against the welfare of a hen. Our data shed light on a long-standing philosophical debate about the relationship between animal welfare and human ethics. We confirm that subjects with higher interests in the hen's well-being exhibit higher moral standards towards humans. Supporters of intensive farming are significantly less prosocial and open-minded, and more Machiavellian than others.
\end{abstract}

\section{INTRODUCTION}

With technological progress, animal farming has changed considerably. Beginning in the late nineteenth century and paralleling the radical changes of the Industrial Revolution, intensive animal farming soon replaced more

\footnotetext{
${ }^{*}$ We would like to thank Armin Falk, Steffen Huck, Clemens König, Frank Rosar, Julia Rose, David Schindler, Klaus M. Schmidt, Nikolaus Schweizer, Peter Singer, Mark Westcott and seminar audiences in Munich and Jerusalem for valuable comments. Jannis Engel and Elisabeth Roth provided excellent research assistance. We also thank Elke Hofmann for organizational support. Florentin Krämer acknowledges funding through the International Doctoral Program "Evidence-Based Economics" of the Elite Network of Bavaria.

${ }^{\dagger}$ Corresponding author.
} 
traditional forms of agriculture. Two discoveries were essential for this development: synthetic vitamin production enabled farmers to raise chickens indoors (Gordon, 1996), and animals needed to be given less space since contagious diseases could be contained by means of antibiotics and vaccines.

Despite its obvious advantages, including cheaper and more efficient production, it has long been recognized that intensive animal farming has severe deficiencies when it comes to ecological consequences and results in hardship for the animals involved. Some farmers have therefore returned to traditional forms of agriculture, which have become known as organic in order to highlight the distinction to intensive farming practices. At the same time, demand for organically produced food has increased substantially and continues to grow (cf. Thompson, 1998).

What motivates consumers to purchase organic food? Some may genuinely care about animal welfare and intend to support species-appropriate and sustainable farming. Yet increasing demand for organic food could also be driven by other, self-oriented, reasons: customers may sometimes follow advertisements without much reflection. Further, they may be motivated by health concerns, e.g. aiming at minimizing meat consumption of animals that received antibiotics. Consumers may also want to project a favorable image of themselves onto their peers if they are part of a subgroup that cares about animal welfare. In short, demand for organic products could result either from entirely selfish motives, or from environmental factors and/or a genuine interest in animal welfare. ${ }^{1}$

To disentangle between these possible causes, it does not suffice to look at scanner data or aggregate market shares of organic products. Likewise, hypothetical questionnaire studies have been criticized for measuring intent rather than behavior. In a rather stark example, Cowe and Williams (2000) find a preference for sustainable consumption among $30 \%$ of their sample in questionnaires, but only a $3 \%$ market share of goods that are produced according to ethical standards in the reference market (UK). ${ }^{2}$ This suggests that questionnaire studies are misleading when it comes to measuring the market share of organic products. They may be even more inaccurate when assessing motivations for ethical purchase behavior, as social desirability would likely bias responses away from image concerns and towards more socially accepted motivations.

To close this gap in the literature and to better understand what motivates consumers to purchase organic foods, we elicit concern for animal welfare in an incentivized, direct and real setup, in a task that allows to abstract from self-oriented motives. Subjects choose between intensive farming and organic farming for a living laying hen. Opting for organic farming is costly, yet guarantees better food, daylight, and much more space to the hen. This procedure allows us to elicit subjects' willingness to pay for transferring a hen to an environment that is better suited to its needs. ${ }^{3}$ Full anonymity and a single-blind

\footnotetext{
${ }^{1}$ We use the term 'animal welfare' to encompass a general disposition to care about living conditions of animals. The exact definition depends on our measure of the willingness to pay for better living conditions of animals and will be explained in detail below.

2 This so-called "30:3 syndrome" or "ethical purchase gap" has been independently verified by other authors, such as Nicholls and Lee (2006). See Bray et al. (2010) for a review.

${ }^{3}$ While opting for organic farming is a clear statement of opting for animal welfare, one may also see it as a decision in favor of sustainability. Defining sustainability is an elusive task. Yet
} 
experimental design ensure that our results are not diluted by image concerns or experimenter demand effects. We can therefore isolate concern for organic agriculture and animal welfare from other more self-oriented factors that could be at play when purchasing organic food at a supermarket.

The gap between questionnaire results and buying decisions may partly arise from the fact that it is cheaper to claim that one cares about animal welfare if it is costless (Bray et al., 2010; Carrigan and Attalla, 2001; Nicholls and Lee, 2006). This is why we establish a real tradeoff: money versus organic living conditions for a hen. Yet in addition to introducing money as an exchange medium, specific market structures may also affect decisions via other channels. Our setup deliberately abstracts from these channels, as their influence could easily vary depending on the specific market design.

For example, we abstract from the effects of advertisement. Through advertisement, people's attention may be directed to aspects of an animal product other than the living conditions of the animals. Similarly, firms may exploit consumers' limited availability of cognitive resources by making certain attributes of products more salient (Bordalo et al., 2013; Gennaioli and Shleifer, 2010). Furthermore, consumer behavior may be very different depending on whether consumers buy in a small shop or in a large supermarket. In the latter, they may feel less responsible for their buying behavior as they can share feelings of guilt with many other customers and receive more social information (Latané and Nida, 1981; Bandura, 1999; Rothenhäusler et al., 2015). In addition, large markets extend the scope for consumers to apply replacement logics: Consumers might be prone to argue that even if they abstain from buying factory-farmed animal products, other consumers will buy. Similar reasoning leads to 'justification from substitution' (cf. Sobel, 2010; Falk and Szech, 2014).

We find that subjects are willing to pay 14 Euros for animal welfare on average. There is substantial heterogeneity in our measure: while $37 \%$ of subjects are willing to pay 25 Euros (the highest amount we allowed for) in order to put a laying hen into better living conditions, $15 \%$ are not willing to pay anything.

We also investigate what kind of people care about animal welfare when directly exposed to the decision between self-interest (i.e., money) versus improving the living conditions of a laying hen.

Intensive farming environments keep animals away from daylight and soil and provide only limited living space. Compared to traditional animal husbandry, intensive farming requires less human labor and allows farmers to produce more meat and other animal products in shorter time spans and in greater quantity. At first glance, intensive farming therefore seems to be an

one may consider a responsibility towards other species and the ecosystem as an important constitutent of sustainable behavior. For instance, the UN follow a three pillar approach with regard to sustainability: "Consisting of three pillars, sustainable development seeks to achieve, in a balanced manner, economic development, social development and environmental protection." (http://www.un.org/en/ga/president/65/issues/sustdev.shtml). In that case, keeping animals in conditions in which they typically die from infections in very short time if they do not receive antibiotics in their feed, and in which they are deprived from nature and daylight, can easily be classified as non-sustainable. We acknowledge that it may not be possible to fully disentangle 'sustainability' and 'ethical responsibility'. These difficulties have been recognized and are widely discussed in the literature, for example by Singhapakdi et al. (1999). For the purposes of this article, however, we remain agnostic about the distinction and view the decision about living conditions as a proxy for both. 
innovative and efficient way to structure production of animal products. It has even been argued that intensive farming may increase social welfare, as cheaper access to animal products could improve human life (McCarthy and Bennett, 1985). Yet one could ask whether this reading of the term 'welfare' is broad enough: first of all, the ecological consequences of industrialized meat production seem worrying (Eisler et al., 2014). Emissions of greenhouse gases, for instance, would likely be substantially lower if animals were held in more appropriate environments, given that the supply of farming land is limited. The same holds for water use. Second, it is at least questionable whether eating animal products improves human health or not, specifically when they make up a large part of people's diets. ${ }^{4}$

Rather than contributing to the discussion about ecological and healthrelated consequences, we aim to understand the social importance of intensive farming. Put boldly: does the support of intensive farming go hand in hand with lower moral standards towards humans?

This question has received considerable attention from philosophers and ethicists, but clean empirical evidence is lacking. In a broad sense, whether there is an association between caring about animal welfare and high moral standards towards humans touches the philosophical debate asking where to legitimately draw ethical boundaries, i.e. which species to include in ethical considerations. Although our study does not claim to provide an answer to this very general question, we provide evidence that in the specific context we consider, enabling a laying hen to live in a more suitable environment goes hand in hand with a more empathic, prosocial, and value-oriented personality towards other human beings.

Philosophers like Aquinas, Locke and Kant hypothesized that there could be a link between the willingness to accept the suffering of animals and the willingness to accept human suffering. For example, Immanuel Kant argues that an appropriate treatment of animals is not a means in and of itself, but rather an instrument to ensure peaceful relations among humans (Adams et al., 2011). Aquinas postulates: "If in Holy Scripture there are found some injunctions forbidding the infliction of some cruelty toward brute animals ... this is either for removing a man's mind from exercising cruelty towards other men ... or because the injury inflicted on animals turns to a temporal loss for some man ..." (Francione, 1995, p. 6). With regard to educating children, Locke advises parents that "...the custom of killing and tormenting of beasts, will, by degrees, harden their minds even towards men." (Locke, 1996, p. 90). More recently, Singer (1995) has argued that human ethics should extend to certain animals on the grounds that great apes, for instance, clearly show signs of intelligence and are similar to humans in their ability to suffer. Researchers have hence speculated that there could be a strong link between caring about animal welfare and human ethical rights.

If there is a link between treating animals well and respecting moral standards towards other humans, debate of intensive farming must include potential effects on human social behaviors, besides pure efficiency arguments. In fact,

4 For instance, a large, prospective study by Kelemen et al. (2005) finds that deaths resulting from coronary heart disease decrease by $30 \%$ when study participants substitute vegetable for animal protein. 
the notion of efficiency may be too narrow in this context, as moral consequences are outside its scope. However, the difference between humans and animals is often stressed as the demarcation line of ethics, suggesting that caring about animal welfare and behaving ethically towards other humans are two completely distinct issues.

For example, René Descartes proposed a mechanistic view of animals, which became rather popular in his time: To him, animals were automata, without soul or mind (Descartes, 1996). In many religions, animals are often depicted as soulless creatures with few or no signs of intelligence. Aristotle established a clear hierarchy of humans over animals, arguing that the latter were made for the sake of human beings. ${ }^{5}$ In addition, several defining aspects of humans, such as memory, self-awareness, and the ability to deliberate and carry out plans that reach far into the future, are frequently pointed out as constituting the boundary between beings that should and beings that should not be included in ethical considerations. Following such arguments, it has been concluded that ethical considerations should only apply to humans, and that the treatment of animals may be rather unrelated to how humans treat other humans (Wise, 2014). Our findings contradict the latter views in the following sense. There is a significant, positive association between caring about animal welfare and moral standards.

The setup of our experiment is simple. Participants are directly exposed to the decision between self-interest (money) versus improving the living conditions of a laying hen. If subjects opt for money, the hen will live under minimal legal standards, i.e., in intensive farming. If subjects forgo the money, the hen will instead live in an organic farming environment for the rest of its life, with access to daylight and soil, much more space, and organic feed without antibiotics. ${ }^{6}$ Subjects know that the organic living conditions are certified and controlled by Naturland, a well-known labeling scheme for high organic farming standards in Germany. ${ }^{78}$ We elicit decisions for various amounts of money in a price list, with monetary amounts increasing from 0.5 to 25 Euros. For each monetary amount, subjects decide between receiving money and exposing the hen to intensive farming conditions versus receiving no money and organic living conditions for the hen. Subjects know that one of their decisions is randomly drawn and implemented with all consequences.

As a measure of moral dispositions towards humans, we elicit subjects' tendencies to behave in Machiavellian ways. Machiavellianism, named after the 15th century philosopher and politician Niccolò Machiavelli, includes characteristics such as the willingness to manipulate others, behave opportunistically,

${ }^{5}$ In contrast, Pythagoreans believed that souls could migrate from human to animal bodies. They accordingly stressed the importance of treating animals well Wise (2014).

${ }^{6}$ The preventive use of antibiotics is ruled out by Naturland regulations. The regulations do allow for antibiotic treatment if animals become ill, but conditions are very strict: farmers must first use natural remedies. Only if these treatments do not take effect can antibiotics be used in very limited quantities. If laying hens are treated with antibiotic substances more than once a year, their eggs cannot be labeled and sold as organic. (http://www.naturland.de/verbraucher.html).

7 "Naturland's farmers and processors work to the highest organic standards, which are even more stringent than the legal requirements imposed by the EC Organic Directive."(http://www. naturland.de/ourdistinguishingfeatures.html).

${ }^{8}$ Of course, it remains debatable whether keeping animals in husbandry is acceptable at all. For a discussion, see, e.g., http://www.albertschweitzerfoundation.org. 
neglect morals and show little affect in social interactions with other humans (Christie et al., 1970). Machiavellianism has been measured in various studies and was found to correlate with economic opportunism (Sakalaki et al., 2007), lying (DePaulo and Rosenthal, 1979) and delinquency (Muris et al., 2013). Machiavellianism therefore serves as a validated measure of immoral and antisocial dispositions.

To enable a closer look at the personalities of our participants, we elicit neuroticism, extraversion, openness to experience, agreeableness and conscientiousness as part of the Big Five Personality Inventory. Agreeableness can be linked to compassion, empathy, altruism and an interest in other humans' wellbeing (Costa and McCrae, 1992). Agreeableness, like openness, is also associated with personal values such as humaneness and goodness (Olver and Mooradian, 2003), as well as prosocial motivations (Graziano et al., 2007). Openness has also been associated with empathy and emotional intelligence (Del Barrio et al., 2004; Van der Zee et al., 2002). People who can easily imagine what life in intensive farming must be like for an animal may tend to save the hen from such living conditions. As such, more open personalities can be expected to have a higher willingness to pay for animal welfare. Thus, the openness-agreeableness nexus serves as a second validated measure of other-regarding moral values and attitudes. ${ }^{9}$

Our data reveal that there is indeed a strong link between caring about animal welfare and standards in ethical behavior towards humans. Subjects willing to forgo higher amounts of money for the hen's sake score lower in the Machiavelli test and hence exhibit more moral, social dispositions towards humans. Furthermore, subjects who care more about the hen also show higher levels of openness in the Big Five Personality Inventory (Costa and McCrae, 1992). Hence, we find that people interested in animal welfare also tend to care more about the well-being of other humans and are more likely to have an altruistic, cooperative personality. In addition, we find that people oriented towards more market-friendly political parties care less about animal welfare and tend to opt for the selfish monetary amount. Maybe these subjects are used to think mostly about direct costs and benefits and, and do not figure in the well-being of an obviously very weak third party, in this case the hen.

Our paper fits into a recent literature discussing morality in economic transactions. Bartling et al. (2015) conduct two experiments in Switzerland and China to study whether participants have preferences for socially responsible behavior when interacting in markets. Their findings indicate that both consumers and producers are indeed willing to reduce negative externalities imposed on third parties, as in $45 \%$ of all transactions the more expensive but externality-free product is traded. Yet they also attest that the willingness to reduce externalities is higher still in non-market contexts, which speaks to the erosion of moral values through markets that had previously been confirmed by Falk and Szech

\footnotetext{
9 Olver and Mooradian (2003) concisely summarize research on these personality traits as follows: "[...] the extant empirical studies generally suggest that the more intellective traits of Openness, Agreeableness, and Conscientiousness relate systematically to Values. Specifically, trait Openness to Experience predisposes individuals toward values related to Openness to Change and Self-Transcendence (most specifically, Stimulation, Self-Direction, and Universalism) versus those related to Conservation and Self-Enhancement (Tradition, Conformity, Security, and Power)." (pp. 114).
} 
(2013). In their experiment, subjects decide between saving the life of a mouse versus receiving 10 Euros and agreeing to kill the mouse. This task is used as a direct, incentivized measure of moral transgression (see Deckers et al. (2016) for validation). While the task bears some resemblance to ours, killing a vertebrate without justification and appropriate qualifications is forbidden by law in many countries, including Germany. ${ }^{10}$ In Falk and Szech (2013), subjects are thus confronted with a decision that is perceived as morally relevant by many, and that risks breaking some taboo (Bénabou and Tirole, 2011) in the sense that an animal is killed without intending to eat it or defending oneself against a potential threat (as could be the case for a rodent in the house). Deciding between money and better living conditions for a laying hen, in contrast, is very similar to many consumption decisions we face on a daily basis and does not violate any conventional norm. The two tasks therefore address different aspects of moral behavior.

\subsection{Methodology}

We use a controlled laboratory experiment to study whether subjects have a positive willingness to pay for animal welfare, after correcting for situational factors. After eliciting their willingness to pay, we ask participants to respond to well-validated and frequently used questionnaires in order to measure their ethical attitude towards other human beings. To the best of our knowledge, we are the first to use a fully incentivized, direct and real setup to study questions relating to animal welfare.

Previous studies on the relationship between personality traits, demographic factors and ethically responsible behavior are typically affected by some methodological features that are worth discussing in more detail. Most importantly, the dependent variable in the bulk of previous research has been constructed with the help of scenarios or vignettes. ${ }^{11}$ As noted, for instance, by Marshall and Dewe (1997), the validity of the conclusions drawn from these types of hypothetical situations rests on two assumptions: (i), the scenario presented to respondents actually constitutes an ethical dilemma, and (ii), the context of this scenario is viewed in comparable ways by the respondents. In addition, the elicitation of moral behavior is not immune to social desirability concerns, rendering a separation from intentions and actual behavior virtually impossible. In the context of ethical decision-making, this bias is especially worrisome. In hypothetical scenario and survey studies, the cost of presenting oneself as an individual that adheres to social norms is low. However, as evidenced by the gap between the willingness to engage in ethically responsible purchase

${ }^{10}$ Compare the German "Tierschutzgesetz" (Protection of Animals Act) as well as Art. 20a of the German constitution.

${ }^{11} \mathrm{O}$ 'Fallon and Butterfield (2005) find that $55 \%$ of the 174 studies they analyze use hypothetical scenarios or vignettes in order to elicit a measure for ethically responsible behavior, while less than $4 \%$ of the results are based on lab studies or field experiments. Other ways to measure ethical behavior include asking subjects to assess their own behavior or the conduct of firms, as judged by internal audits (p. 404). 


\begin{tabular}{|c|c|c|}
\hline & Conventional & Organic \\
\hline $\begin{array}{l}\text { grassy outdoor } \\
\text { runs }\end{array}$ & no & $\geq 43$ sqft. per hen \\
\hline $\begin{array}{l}\text { canopied outdoor } \\
\text { area }\end{array}$ & no & $\begin{array}{l}\text { available year-round, } \\
\text { possibility to sand- } \\
\text { and dust-bathe }\end{array}$ \\
\hline size of coop & up to 6000 hens & up to 3000 hens \\
\hline feed & $\begin{array}{l}\text { conventional agriculture, } \\
\text { antibiotics allowed }\end{array}$ & $\begin{array}{l}\text { organic agriculture, } \\
\text { no antibiotics allowed }\end{array}$ \\
\hline
\end{tabular}

TABLE 1.-Comparison of Living Conditions

behavior and actual purchases, desired behavior does not necessarily match observed behavior. We address these potential concerns by designing an appropriate experimental environment and by introducing a trade-off between ethical behavior and monetary disutility.

\subsection{Design}

In order to elicit the degree to which subjects care about animal welfare, they trade off a monetary benefit against the welfare of a hen. Subjects decide between organic living conditions for the laying hen and forgoing a monetary amount versus conventional agriculture (intensive farming) for the hen and receiving a monetary amount.

Subjects know that if they opt for organic farming, the hen will live in a Naturland-certified farming environment. To be certified as organic egg producers, farms have to guarantee high standards with regard to ecologically sustainable production and are not allowed to add antibiotic substances to the feed. Subjects are informed that our farm is certified as an organic "Naturland" producer. This label is only given to farms fulfilling criteria that are substantially stricter than those prescribed by EU regulations. Conversely, conventional agriculture refers to legal minimum standards for livestock breeding.

Subjects know that the hen has been entrusted to their care. To make the decision more salient and to bridge the gap from the laboratory to a more natural environment, they are shown two pictures of a hen (Figure 3 in Appendix A).

Moreover, the two possible living conditions, conventional versus organic farming, are described in detail and summarized in a table (Table 4).

After being exposed to the information on living conditions and the implications of their choices, subjects decide between monetary amounts versus animal welfare. They decide on a price list. In each decision row, they can opt for conventional living conditions for the hen and a monetary amount versus organic farming and no monetary amount. Monetary amounts increase over decision rows, from 0.5 Euros to 25 Euros in 0.5 Euro increments. Subjects know that one of their choices will later be randomly drawn in order to determine their payoff. They can hence guarantee organic farming to the hen by 
always choosing the organic option. We include example payoff calculations and control questions to make sure that subjects understand the task. ${ }^{12}$

Choosing the price list method rather than a fixed monetary amount enables us to study subjects' willingness to pay for sustainable farming and a better life for the hen. The switch point, i.e. the amount of money at which subjects switch from organic to conventional agriculture, can hence be interpreted as how much money subjects are willing to forgo in order to enable a hen to live in a more sustainable and more appropriate environment. ${ }^{13}$

Since the consequences of their actions are not directly observable to participants in our experiment, we take care to state that their choices will be carried out exactly as specified in the instructions. To emphasize this point, we repeat the corresponding paragraph in oral form and inform subjects that they will be able to verify all facts after the experiment. To reduce experimenter effects, all sessions are conducted by a research assistant who is blind to the hypotheses of this study.

Another aspect of our study is worth noting. While subjects take an incentivized choice about the animal, we elicit moral dispositions towards humans via well-established test questions. We chose this combination of elicitation methods for the following reasons. If subjects first decided about forgoing money to improve an animal's welfare and then took a real-life decision in an ethical context (e.g. forgoing money to help a human being versus taking the money), the first decision could easily affect the second. This so-called 'conscience accounting' is reminiscent of the 'trade in pardons' used by the medieval Catholic church to raise money, and has recently been confirmed experimentally by Gneezy et al. (2014). In particular, if subjects made a strong link between animal welfare and human ethics, which is what we aim to explore in this study, subjects with a bad conscience from harming the animal could decide to help the human in the second step just to ease their bad conscience and thereby obtain a better self-image (Bénabou and Tirole, 2011). This is why we rely on validated questionnaires to elicit moral and prosocial dispositions instead of providing a second task with another real third party that may be helped or harmed.

\subsection{Procedures}

The experiment was conducted at the University of Bamberg on two consecutive days in February 2013 with a sample comprising predominantly students. In total, 216 subjects (117 female, 94 male, 5 unidentified) participated in one of five sessions with an average duration of 105 minutes. Average earnings were approximately 13 Euros, including a show-up fee of 4 Euros. Participants were recruited via ORSEE (Greiner, 2004).

Subjects received written instructions for the experiment. Before receiving the instructions, they read a text on free will, religion, or brain activities. Texts

\footnotetext{
${ }^{12}$ Translated instructions are included in the Appendix. Instructions in the original language (German) are available from the authors upon request.

${ }^{13}$ Subjects who always choose the monetary reward (i.e., never choose organic farming) are assigned a switch point of 0.5 Euros. Accordingly, subjects who always choose organic farming are assigned a switch point of 25.5 Euros.
} 
were randomly allocated and constitute our treatment conditions. Since switch points do not differ across conditions, we collapse the data in order to obtain a broader basis for our study (see Appendix B for details on the text treatments and statistical tests showing that $p$-values are not significant on any conventional level). All analyses are replicated on the control sample (see Appendix C).

After all subjects had filled out the price list, they were asked to complete the Big Five Personality Inventory (Costa and McCrae, 1992), a test for Machiavellian personality traits (Christie et al., 1970), the Bem Sex Role Inventory (Bem, 1981) and a series of demographic questions. In order to motivate subjects to respond to these questions with proper attention, we incentivized this stage by paying an additional 3 Euros.

\subsection{Implementation}

In order to implement the decisions taken by the subjects in our experiment, we cooperated with two local egg farmers. One of these egg producers keeps the laying hens in large coops that are run according to conventional standards. The other, neighboring, egg farmer is certified as organic according to the high standards of Naturland. We arranged that for each hen involved in our study, two places were kept open: one in intensive farming, one in the organic environment. We opted for this solution as it ensures that there is no scope for a replacement argument, meaning that the remaining capacity is not filled up with other hens. For each hen, there are two living options, and the one that is not chosen by subjects remains unfilled.

\section{PREDICTIONS}

Our research design allows us to study correlations between individual characteristics and our measure of ethical behavior, the switch point. We derive hypotheses concerning the direction of effects in the following section.

\subsection{Personality Traits}

Personality traits are generally more difficult to observe than demographic and socioeconomic information, yet they often exhibit a higher degree of predictive power (De Pelsmacker et al., 2005; O'Fallon and Butterfield, 2005). The availability of validated and often used scales enables us to identify key personality factors that are likely to play a role for moral judgment. We concentrate on two standard measures: Machiavellianism (Mach-IV) and the Big Five Personality Inventory (NEO-FFI). Both have been extensively analyzed in various contexts. We also include the Bem Sex Role Inventory (BSRI) to explore whether self-ascribed gender roles have an impact on willingness to pay for animal welfare, over and above that of biological gender.

Machiavellian characters exhibit a high willingness to manipulate others, behave opportunistically, neglect morals and show little affect in social interactions (Christie et al., 1970). Machiavellianism as a personality construct is generally considered to consist of three dimensions, reflecting different themes 
in the original writings upon which the Machiavelli scale is based: "The first theme was the endorsement of such manipulative tactics as the use of flattery and deceit in interpersonal interactions. The second theme was a cynical view of human nature in which others are regarded as weak, untrustworthy and selfserving. The third theme was a disregard for conventional morality." (Fehr et al., 2013, p. 78). The Mach-IV scale we use accounts predominantly for the first two themes. ${ }^{14}$ We therefore compute scores for 'tactics' and 'cynicism' separately and include them as two regressors in our analyses. ${ }^{15}$

Machiavellianism has been shown to be negatively associated with ethical decision making and behavior (Ford and Richardson, 1994; O'Fallon and Butterfield, 2005). People who score high on the Machiavellianism scale are more likely to evaluate unethical behavior as appropriate if it is effective in achieving a personal goal than people with low scores (Geis and Moon, 1981; Singhapakdi and Vitell, 1990). Furthermore, machiavellistic people exhibit a higher propensity to lie (DePaulo and Rosenthal, 1979). Kahane et al. (2012) suggest that such unethical behavior may be rooted in a lack of empathy and lack of aversion to harm others. Thus, if there is a link between moral standards in social interactions with humans and caring about animal welfare and sustainability, Machiavellianism should be negatively associated with decision making that enhances animal welfare and provides more sustainable living conditions to animals. We accordingly expect subjects with high Machiavellianism scores to care less about the living conditions of their hen.

Of the five personality dimensions that Costa and McCrae (1992) identify as basic traits, openness and agreeableness are most closely related to empathic behavior and prosocial motivation. In their Big Five inventory, Costa and McCrae (1992) describe an agreeable person as being sympathetic, interested in the well-being of others and compassionate. They further link agreeableness to characteristics such as empathy and altruism. It is hence not surprising that agreeable individuals are reported to be prosocially motivated (Graziano et al., 2007; Wilkowski et al., 2006).

Openness as a concept is rather difficult to grasp, but there is wide-ranging agreement that it refers to a personality with strong beliefs in values, a perceptive and curious intellect, and a liberal, adventurous, and empathic mindset (McCrae and Costa, 1997). The link between openness and empathy has also been established by Del Barrio et al. (2004), and it has been shown that subjects who score high on the openness facet possess higher levels of emotional intelligence (Van der Zee et al., 2002).

Taken together, these results suggest that if there is a relation between moral behavior and caring about animal welfare, subjects scoring high on agreeableness and openness will make more animal welfare-enhancing and sustainable decisions. We thus hypothesize that agreeableness and openness will correlate positively with the amount of money subjects are willing to forgo to increase a hen's living conditions.

${ }^{14}$ Only two out of 20 questions refer to the morality dimension. Any measurement of this subfactor by means of the Mach-IV scale is therefore bound to suffer from low precision.

${ }^{15}$ This procedure is also recommended by Fehr et al. (2013), who provide a thorough review of the literature spawned by the Machiavellianism scale from 1971 to 1987. 
An exploratory questionnaire we use in our study is the Bem Sex Role Inventory (BSRI). The BSRI is a very useful instrument to abstract from biological gender and instead focus on self-ascribed sex roles that range from rather masculine to rather feminine. The questionnaire consists of a series of attributes that are usually associated with feminine or masculine behavior. Several questionnaire studies have suggested that females may behave in more ethical ways than males, while other studies find no significant correlation between biological gender and morality (for instance, Chung and Trivedi (2003) and Ross and Robertson (2003) report significant results confirming the positive association between female gender and morality, while in the majority of scenarios in Lund (2000) and Radtke (2000) there is no gender difference in behavior). Besides biological gender, we are interested in sex roles in order to see whether self-ascribed gender may play a role for decision-making.

\subsection{Demographic Variables}

As indicated above, demographic criteria are often found to possess low explanatory power for ethically responsible or sustainable behavior. For instance, a study by Straughan and Roberts (1999) examines the link between demographic and psychographic criteria with ecologically conscious behavior. They find that psychographic criteria are much better suited to explain observed variation in the dependent measure than demographic factors.

Our results are largely in line with this general tendency. Across the spectrum of demographic questions we posed, only those that are highly correlated with personality traits (like being a vegetarian) possess predictive power.

We define the switch point to be the first decision where a subject switches from the organic to the conventional agriculture option. A total of 16 out of 216 subjects switch between the two options multiple times, and are classified accordingly. We exclude 19 out of the remaining 200 subjects because they switch from conventional to organic farming. These subjects either preferred intensive farming to organic farming, or they did not understand the task. Including multiple switchers, this leaves 197 subjects in the sample. If subjects switch more than once, we impute their willingness to pay by taking the first switch point as a proxy. As a robustness check, we also present analyses on the sample without multiple switchers, which comprises 181 subjects.

Table 2 summarizes main demographic characteristics of the subjects used in this study.

In order to test our predictions, we present regressions with the willingness to pay for animal welfare as dependent variable and personality measures as well as demographic information as regressors. As is evident from Figure 1, the dependent variable is censored both from above and from below. ${ }^{16}$ This would result in an inconsistent estimator when using OLS. To deal with censored data,

${ }^{16}$ The empirical probability density function of the switch point has mass points both at 0.5 Euros and at 25.5 Euros. It is therefore likely that a significant fraction of subjects would have been willing to pay more than 25.5 Euros in order to ensure better living conditions for the hen, 


\begin{tabular}{lcccccc}
\hline & \multicolumn{3}{c}{ MEN } & \multicolumn{3}{c}{ WOMEN } \\
& $\varnothing$ & $\sigma$ & $N$ & $\varnothing$ & $\sigma$ & $N$ \\
\hline Age & 23.79 & 3.09 & 84 & 23.38 & 3.50 & 106 \\
Vegetarian & 0.10 & 0.30 & 84 & 0.20 & 0.40 & 106 \\
Vegan & 0.01 & 0.11 & 84 & 0.01 & 0.10 & 106 \\
Religiosity Index & 0.39 & 0.20 & 84 & 0.38 & 0.19 & 106 \\
\hline
\end{tabular}

TABLE 2.-Summary Statistics

Tobin (1958) proposed a maximum likelihood estimator that Amemiya (1973) subsequently proved to be consistent. We therefore report regressions using the Tobit model.

\subsection{Willingness to Pay for Animal Welfare}

As pointed out before, the nature of our task allows for a clean identification of willingness to pay for animal welfare. We explicitly abstract from advertisement and replacement effects and suppress image concerns by ensuring full anonymity. Our data indicate that the median subject is willing to pay 11 Euros for animal welfare (the average WTP is 14 Euros).

Visual inspection of Figure 1 reveals substantial heterogeneity in the switch point. About $37 \%$ of participants refuse to accept conventional farming for any amount of money we offered, thereby ensuring organic farming for their hen. On the other end of the spectrum, $15 \%$ of subjects are unwilling to give up any amount of money in order to ensure better living conditions for the laying hen. There is no statistically significant difference between men and women regarding the median and the distribution of the switch point.

As discussed in Section 1, a number of studies have shown a gap between intent to behave in ethical ways and actual behavior in the marketplace (cf. Cowe and Williams, 2000; Nicholls and Lee, 2006; Bray et al., 2010). We cannot directly attest to this 'ethical purchase gap', since we lack data on intent. However, according to personal communication with the two cooperating farmers, the average payment of 14 Euros corresponds almost exactly to the additional cost imposed by organic farming relative to conventional agriculture. This suggests that participants have a realistic understanding of the two different conditions and are willing to compensate farmers for additionally incurred costs in full. We may therefore speculate that in our sample, the willingness to pay for organic farming conditions is sufficiently high in order to induce the majority of subjects to buy organic even in the marketplace.

\subsection{Animal Welfare and Human Ethics}

The central question we aim to answer with our study concerns the social importance of intensive animal farming. Our results show that lower moral

while an equally significant (yet not quite as large) fraction of subjects may exhibit a negative willingness to pay for animal welfare. 


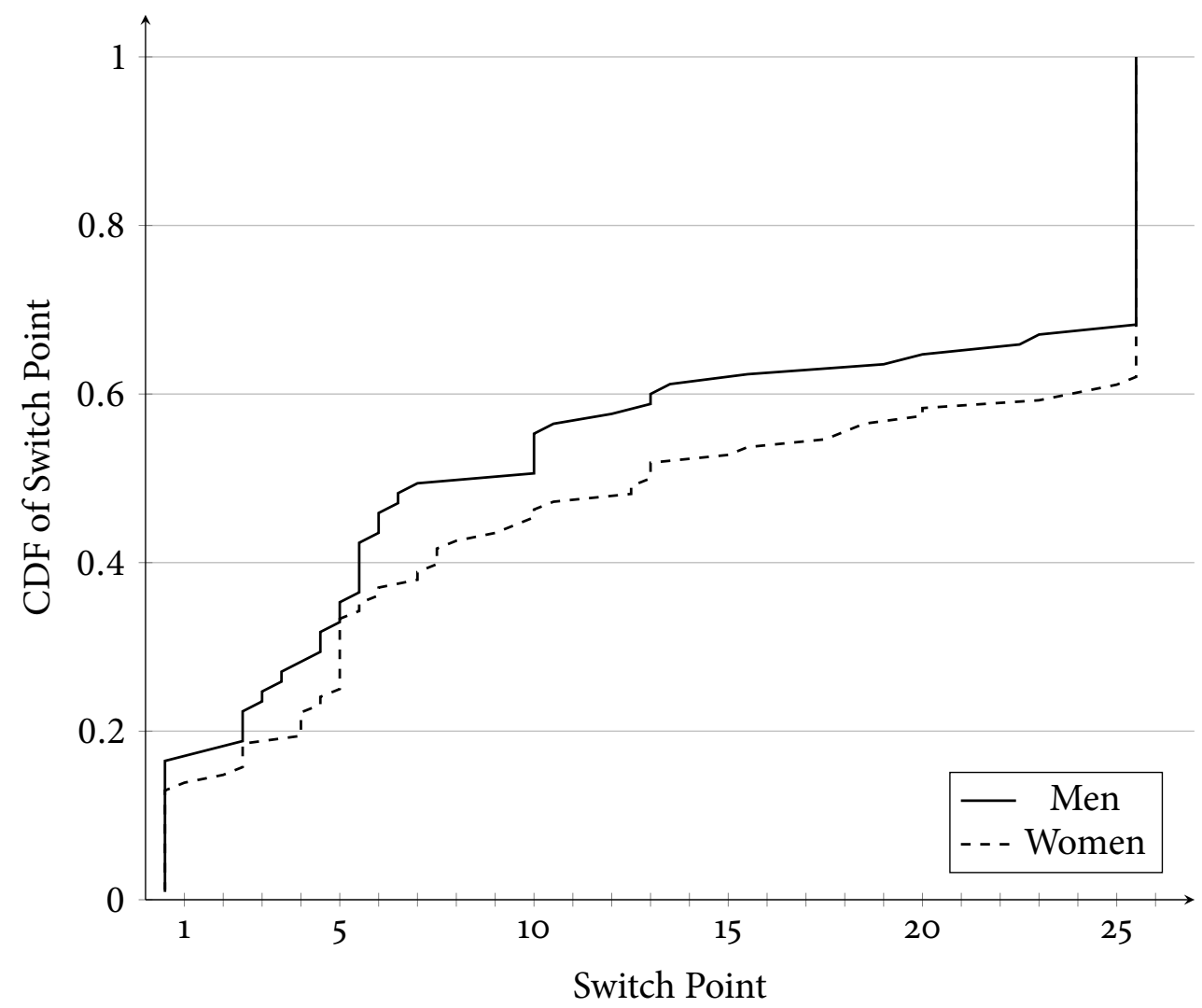

Figure 1.-Empirical Cumulative Density Function of the Switch Point by Gender

standards towards humans are indeed associated with less concern for animal welfare. This enables us to speak to a long-running debate about the relationship between animal and human cruelty. For instance, Kant makes the following empirical claim: "If he is not to stifle his human feelings, he must practice kindness towards animals, for he who is cruel to animals becomes hard also in his dealings with men." (Gruen, 2014). It is certainly true that Kant claims a causal relationship that we cannot show, referring to a kind of virtue ethics in the sense that good behavior needs to be trained. However, we do fail to reject the hypothesis by showing that there is a correlation between animal welfare and ethical standards towards humans. 


\begin{tabular}{|c|c|c|c|c|}
\hline & \multicolumn{2}{|c|}{ Excl. Multiple Switchers } & \multicolumn{2}{|c|}{ Incl. Multiple Switchers } \\
\hline & (1) & (2) & (3) & (4) \\
\hline Openness & $\begin{array}{l}0.549^{* *} \\
(0.250)\end{array}$ & $\begin{array}{l}0.473^{*} \\
(0.259)\end{array}$ & $\begin{array}{l}0.517^{* *} \\
(0.218)\end{array}$ & $\begin{array}{l}0.422^{*} \\
(0.230)\end{array}$ \\
\hline Agreeableness & $\begin{array}{c}0.431 \\
(0.416)\end{array}$ & $\begin{array}{c}0.295 \\
(0.414)\end{array}$ & $\begin{array}{c}0.246 \\
(0.344)\end{array}$ & $\begin{array}{c}0.178 \\
(0.338)\end{array}$ \\
\hline Machiavelli (Tactics) & $\begin{array}{c}-0.801^{* *} \\
(0.383)\end{array}$ & $\begin{array}{l}-0.707^{*} \\
(0.401)\end{array}$ & $\begin{array}{c}-0.680^{* *} \\
(0.320)\end{array}$ & $\begin{array}{l}-0.548 \\
(0.336)\end{array}$ \\
\hline Machiavelli (Cynicism) & $\begin{array}{c}0.557 \\
(0.486)\end{array}$ & $\begin{array}{c}0.458 \\
(0.484)\end{array}$ & $\begin{array}{c}0.302 \\
(0.388)\end{array}$ & $\begin{array}{c}0.163 \\
(0.386)\end{array}$ \\
\hline Locus of Control & $\begin{array}{c}-0.304 \\
(0.230)\end{array}$ & $\begin{array}{c}-0.223 \\
(0.227)\end{array}$ & $\begin{array}{c}-0.286 \\
(0.202)\end{array}$ & $\begin{array}{l}-0.210 \\
(0.199)\end{array}$ \\
\hline Masculinism Score & $\begin{array}{c}0.158 \\
(0.192)\end{array}$ & $\begin{array}{l}0.0512 \\
(0.188)\end{array}$ & $\begin{array}{c}0.143 \\
(0.174)\end{array}$ & $\begin{array}{l}0.0559 \\
(0.171)\end{array}$ \\
\hline Feminism Score & $\begin{array}{c}0.217 \\
(0.192)\end{array}$ & $\begin{array}{c}0.203 \\
(0.200)\end{array}$ & $\begin{array}{c}0.163 \\
(0.166)\end{array}$ & $\begin{array}{c}0.155 \\
(0.169)\end{array}$ \\
\hline Age & & $\begin{array}{c}0.580 \\
(0.536)\end{array}$ & & $\begin{array}{l}0.762^{*} \\
(0.459)\end{array}$ \\
\hline Gender & & $\begin{array}{c}-3.363 \\
(3.733)\end{array}$ & & $\begin{array}{l}-2.590 \\
(3.241)\end{array}$ \\
\hline Vegetarian or Vegan & & $\begin{array}{l}12.47^{* *} \\
(5.812)\end{array}$ & & $\begin{array}{l}9.178^{*} \\
(4.700)\end{array}$ \\
\hline Religiosity Dummy & & $\begin{array}{l}-1.150 \\
(3.600)\end{array}$ & & $\begin{array}{l}-1.352 \\
(3.021)\end{array}$ \\
\hline Constant & $\begin{array}{l}-13.86 \\
(31.32)\end{array}$ & $\begin{array}{l}-16.85 \\
(31.07)\end{array}$ & $\begin{array}{c}-0.00792 \\
(26.42)\end{array}$ & $\begin{array}{l}-10.50 \\
(26.28)\end{array}$ \\
\hline$N$ & 153 & 147 & 168 & 162 \\
\hline$N$ (uncensored) & 68 & 66 & 83 & 81 \\
\hline$N$ (left-censored) & 24 & 22 & 24 & 22 \\
\hline$N$ (right-censored) & 61 & 59 & 61 & 59 \\
\hline Pseudo $R^{2}$ & 0.021 & 0.034 & 0.019 & 0.029 \\
\hline Log Likelihood & -370.8 & -353.4 & -432.1 & -414.7 \\
\hline
\end{tabular}


Put differently, we provide empirical support for Kant's claim that "we can judge the heart of a man by his treatment of animals" (Kant, 1981), which is a necesary condition for the claim that cruelty to animals leads to cruelty towards humans, and an important link in his argument as to why humans should be good to animals.

As measures for ethical dispositions towards humans, we elicited two dimensions of Machiavellianism: a cynical view of human nature and a general disposition to exploit human weakness for personal gains through manipulative tactics (Fehr et al., 2013). The first dimension concerns the perception of others without appealing to the moral views of the respondent himself. The second dimension prods subjects for their willingness to participate in exploitative endeavors, essentially asking them for their willingness to circumvent conventional moral standards to achieve personal gains. We therefore focus on the second dimension (which we term Machiavellianism (Tactics) in the regressions below) to gain insights into subjects' personal attitudes regarding ethical behavior. In addition, we asked subjects to complete the full Big Five personality inventory and use their agreeableness and openness scores as proxies for a general disposition to respect ethical standards and endorse humane and good behavior (Olver and Mooradian, 2003).

Table 3 presents our results. Exactly as predicted, we find a significant negative correlation between the switch point and the tactics dimension of Machiavellianism: The more money a subject is prepared to forgo in favor of organic farming, the higher are his or her standards concerning morals and other-regarding behavior in social interactions with humans. As hypothesized, people who classify as detached from conventional morality and unemotional according to the Machiavellianism (Tactics) scale care less about the hen's living conditions than other subjects. The effect is statistically and economically significant: if the Machiavelli (Tactics) score increases by one point, willingness to pay for animal welfare decreases by 0.8 Euros on average. Measured against the empirical range of scores (with a minimum of 11 and a maximum of 43 ), this implies that a 4 percentage point increase in Machiavellianism results in a 1 Euro decrease in the switch point. To illustrate the magnitude of this effect, someone in the first quartile of the distribution would be willing to pay at least 5 Euros more than a person in the fourth quartile.

As a second measure of moral dispositions towards humans, we elicited the subject's scores in the Big Five facets agreeableness and openness. We expected a strong link between agreeableness and caring about animal welfare. Our data do not support this hypothesis. This may be due to several factors: either the measure of agreeableness as personality construct is imprecise, or it does not measure what it claims to measure, or agreeableness is indeed uncorrelated with caring about animal welfare. Considering the relatively small sample size, we may also not have enough power to detect the effect if it is sufficiently small. The highly significant negative correlation $(\rho=-0.39, p<0.01)$ between the Machiavellianism (Tactics) score and Big Five facet agreeableness lends some support to the latter explanation.

Reassuringly, we do find a link between openness and concerns for animal welfare: a two point increase in openness is associated with a 1 Euro increase in willingness to pay. In terms of the economic significance, this effect is very 
similar to the Machiavellianism effect: subjects in the third quartile of openness are willing to pay at least 5 Euros more for better living conditions than those in the first quartile. Openness is not only associated with characteristics such as creativity, attention to inner feelings and tolerance, but also with goodness and humaneness (Olver and Mooradian, 2003), which are likely to affect behavior towards others. Further, openness is associated with cognitive abilities (DeYoung et al., 2005). Previous research has reported correlations between cognitive ability and the ability to delay gratification (Dohmen et al., 2010), i.e., the ability for future oriented thinking. Cognitive ability, and hence openness, might accordingly also be connected to ecologically sustainable behavior, for which considerations of future outcomes play an important role.

Our results are in line with findings from psychology and sociology that focus on whether there is a link between aggressive behavior towards animals and aggressive behavior towards humans. Research from psychology, psychiatry and sociology suggests that children's aggression towards animals predicts violence against human beings later in life (Felthous and Kellert, 1986; Flynn, 1999, 2000). In a review study, Gullone (2011) investigates the co-occurrence of human-directed and animal-directed aggression and concludes that children and adults who behave aggressively against animals are also likely to act aggressively and show violence against people. Yet if there is a link with regard to aggression, there could also be a link with regard to compassion. Thompson and Gullone (2003) argue that contact to animals and developing a bond with them enhances empathy towards animals in children, which will be transferred to human beings and thus lead to higher prosocial behavior towards humans. Our study shows that indeed, caring about animal welfare correlates strongly with moral dispositions towards human beings. There seems to be a strong relationship between human ethics and a preference for more sustainable, more appropriate living conditions for animals. Conversely, if people are prepared to look away when the welfare of an animal is concerned, they are also likely to look away when a human needs their support and cooperation.

\subsection{Further Exploratory Findings and Validity of Measure}

VEGETARIANISM As a validity check, we investigate the association of the switch point with being a vegetarian. ${ }^{17}$ Following a vegetarian diet can be driven by different motives, including health concerns or religious convictions. Therefore, being a vegetarian does not necessarily have to coincide with caring about animal welfare. We nevertheless expected that many vegetarians would likely have a preference for improved living conditions for the hen. A Wilcoxon rank-sum test confirms that vegetarians show a higher willingness to forgo money for the hen's sake than non-vegetarians $\left(\operatorname{mean}_{\text {non-vegetarian }}=12.84\right.$, mean $\left._{\text {vegetarian }}=16.68, p<0.1\right)$. This association is also apparent in the regressions reported in Table 3. We take this as a sign of validity of our measure of preferences for animal welfare.

\footnotetext{
${ }^{17}$ We did not further differentiate between pesco-vegetarians, ovo-lacto-vegetarians etc. in our questionnaire. We assessed veganism separately, but include these subjects in the vegetarian category.
} 
GENDER DIFFERENCES While the literature on moral behavior does not always reveal a gender difference, it is a standard finding that if there is a difference in gender with regard to ethical or moral behavior, females have the higher standards. ${ }^{18}$ When it comes to caring about animal welfare as measured by switching from organic to conventional farming, we do not observe an overall significant difference between genders $\left(\operatorname{mean}_{\text {female }}=14.29, \operatorname{mean}_{\text {male }}=12.48\right.$, $p=.26)$.

Likewise, we fail to show that feminity (masculinity) assessed with the Bem Sex Role Inventory correlates positively (negatively) with the switch point (see Table 3). Thus, neither biological sex nor self-ascribed sex roles seem to be associated with the willingness to pay for sustainability and animal welfare.

POLITICAL ORIENTATION We do find that switch points differ depending on the political party subjects identify with. The parties covered the entire political spectrum, with the Christian Democratic Union (CDU) being the most conservative option, and the party The Left (Linke) on the far left. Subjects opting for the CDU are likely to have a traditional, conservative view on social life and a market-friendly attitude. The Free Democratic Party (FDP) is a traditional liberal, market-friendly party; The Green Party (Gruene) follows policies directed at environmental protection, while the Social Democratic Party (SPD) is the traditional socialist party in Germany. The party The Left is a left-wing party with a sceptic attitude towards capitalism, and the Pirates (Piraten) represent a more direct democracy and open internet culture.

Interestingly, political orientation bears some explanatory power about who cares about animal welfare. Our results suggest that a tendency towards marketfriendly policies coincides with a low interest in animal welfare, while subjects with a more socialist or environment-oriented political view care more about the living standards of animals (Figure 2).

There is an overall significant difference between switch points according to political orientation (Kruskal-Wallis test, $p<.05$ ). Specifically, subjects with a preference for rather market-friendly parties (i.e. CDU and FDP) are less prepared to forgo money for organic living conditions compared to subjects preferring any other party. ${ }^{19}$ The fact that conventional animal farming is the standard in Germany might serve as an indication as to why subjects with a preference for the conservative party CDU seem to care least about their hen's welfare. Most farm animals have been kept in factory farming conditions over the last decades in Germany. ${ }^{20}$ Hence, following the conventional approach could imply a preference for keeping animals' living conditions as is.

\footnotetext{
${ }^{18}$ Compare the survey articles by Loe et al. (2000) and O'Fallon and Butterfield (2005).

${ }^{19} \mathrm{CDU} / \mathrm{FDP}$ vs. SPD: $p<.05$; CDU/FDP vs. Gruene: $p<.01$; CDU/FDP vs. Piraten: $p<.05$; CDU/FDP vs. Linke: $p<.1$.

${ }^{20}$ According to the German Statistical Office, only $16.7 \%$ of laying hens were kept in free range or organic farming conditions at the time of the latest agricultural census (https: //www.destatis.de/DE/ZahlenFakten/Wirtschaftsbereiche/LandForstwirtschaftFischerei/ Landwirtschaftszaehlung2010/Tabellen/9_3_LandwBetriebeHaltungsplaetzeHuehner.html).
} 


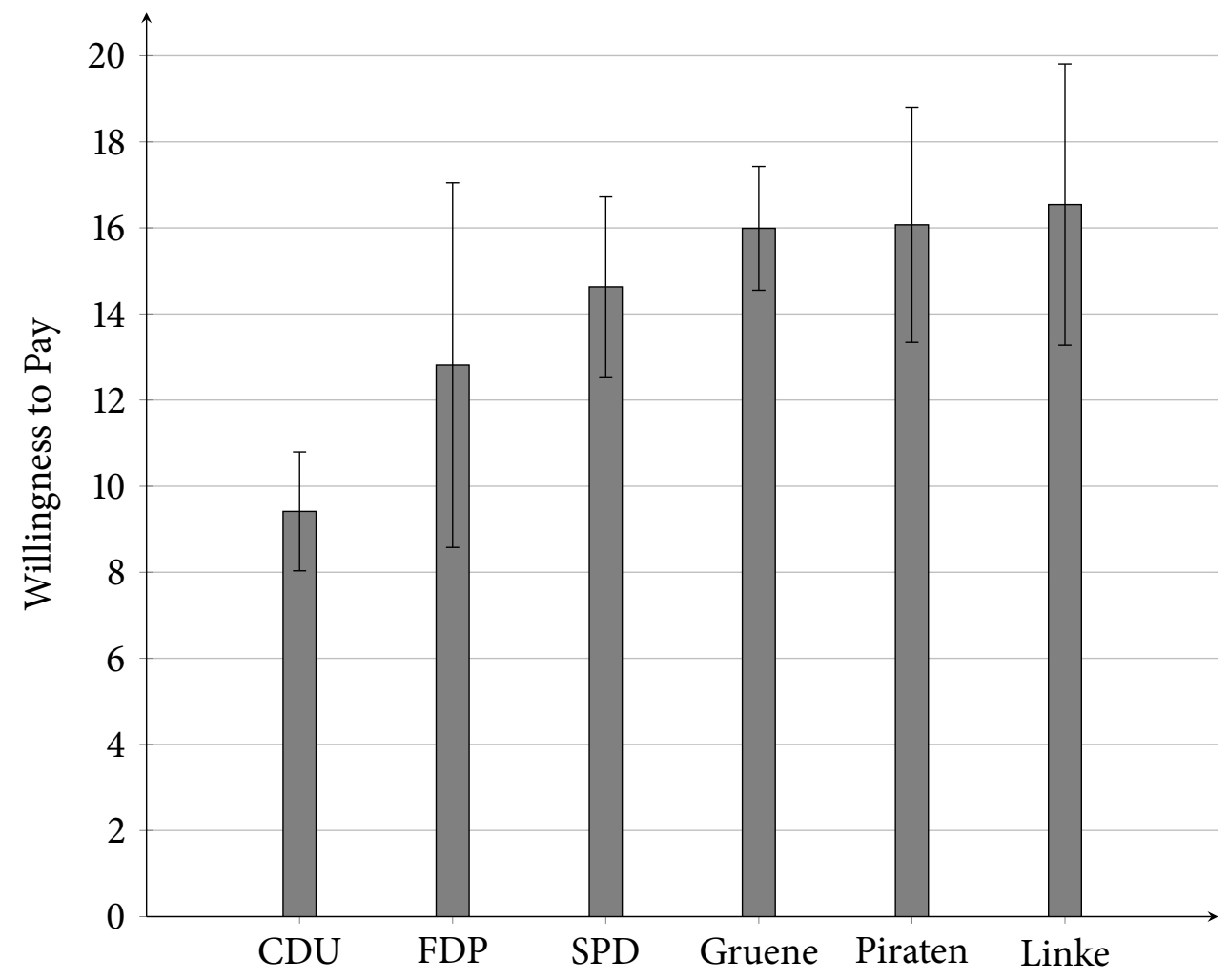

Figure 2.-Animal Welfare and Political Orientation

Notes: Average switch points by identification with political parties. Bars display standard error of the mean. 
The perspective that animals do not possess innate rights to be treated well has a long tradition in philosophy, going back to Thomas Aquinas (12251274). Over the course of the centuries, philosophers like Kant and Locke have confirmed these views, placing animals firmly in the realm of creatures that deserve to be treated well only if it is in the interest of humans. Our results show that caring about the conditions farm animals live in directly relates to acting in accordance with social and moral norms in human interaction.

Our aim in this study was to investigate whether there is a clear link between caring about animal welfare and having high ethical standards in general. Our data confirm that this relation exists. People who care about animal welfare also express higher ethical standards towards human beings.

The design of our study incentivizes decisions about animal welfare by establishing a trade-off between a monetary benefit and the possibility of enabling a laying hen to live in a more appropriate environment. In contrast to scenario or vignette studies that cannot avoid biases due to social desirability concerns, our design therefore allows for a clear identification of subjects' interest in animal welfare, abstracting from self-related aspects like image concerns or social desirability.

Several philosophical treatises have speculated that it is important to treat animals well because such behavior stimulates ethical conduct among humans. Our study stresses that such a link could exist. To our knowledge, this experiment is the first to isolate interest in animal welfare from confounding factors like the market environment and to establish a clean link with Machiavellianism and agreeableness, our measures for ethical behavior towards humans.

In addition, we conducted exploratory analyses, examining the relations between various individual characteristics and caring about animal welfare in order to inform policy makers and social debate. We find that there are pronounced differences in caring about animal welfare depending on which political party subjects like best. Subjects preferring more conservative and market-friendly parties care less about animal welfare. Furthermore, openminded subjects and participants scoring low on the Machiavellianism (Tactics) scale care more about animal welfare than other subjects. Neither biological gender nor self-ascribed sex roles are good predictors for ethically responsible behavior.

As our results rely on a student sample, more research is needed to fully characterize influences of personality and socio-demographics. Nevertheless, our results indicate that there may be a strong relationship between caring about animal well-being and ethical dispositions. 
Thank you for your participation!

For your participation you will receive a base amount of 4 Euros. You will be able to earn additional money in the following experiment. You will receive your money at the end of the experiment in an envelope. Neither the other participants of this study nor the experimenters will be able to see how much money you have received.

Please note: during the entire duration of the experiment, communication between participants is not allowed. If you have a question, please raise your hand. Your question will then be answered privately.

Please note: all statements made in these instructions are true. This is true for all experiments conducted at the Bamberg Laboratory for Experimental Research, and also for this experiment. In particular, all consequences that are described in the instructions will be carried out exactly as described. If you wish, you may verify the correctness of all statements made in these instructions after the experiment.

In this experiment there are two options. Depending on which option you choose, you will be able to earn different amounts of money. In addition, there will be different consequences for a laying hen, depending on your chosen option.

Details Regarding the Laying Hen
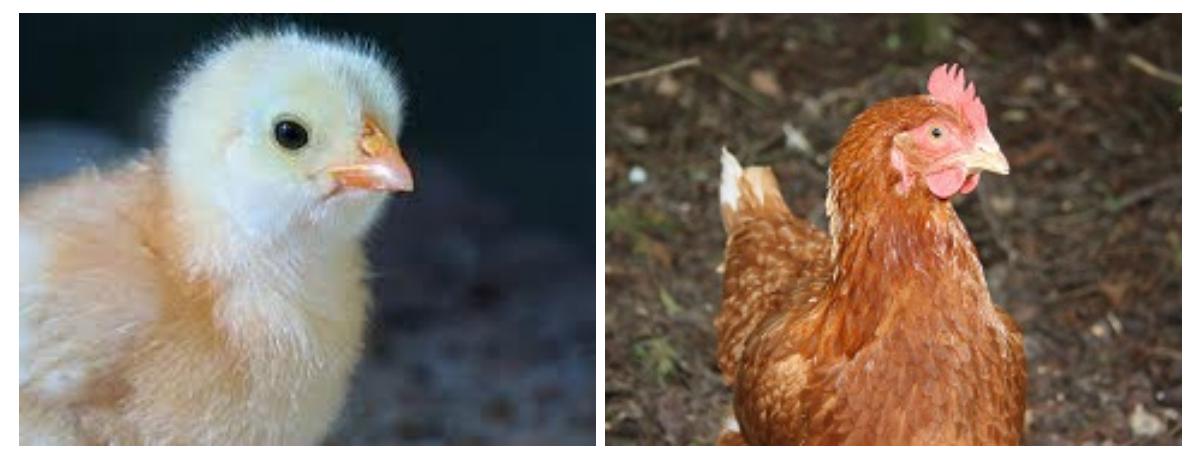

FIgURE 3.-Pictures of a chick and a grown hen.

In this study, a laying hen is entrusted to your care. It is a young and healthy hen. The hen is now old enough ( 18 weeks) to be put into a coop with other laying hens on a Franconian farm. In this regard, there are two options for the laying hen among which you may choose. The hen will live for another approximately 13 months from the time it is put into the coop.

How do the options differ?

Conventional Option: If you choose option conventional, you will receive an additional amount of money at the end of the experiment and the hen will be put into a conventional farming environment.

Organic Option: If you choose option organic, you will not receive any additional amount of money at the end of the experiment and the hen will be put into an organic farming environment. 


\begin{tabular}{|c|c|c|}
\hline & Conventional & Organic \\
\hline $\begin{array}{l}\text { grassy outdoor } \\
\text { runs }\end{array}$ & no & $\geq 43$ sqft. per hen \\
\hline $\begin{array}{l}\text { canopied outdoor } \\
\text { area }\end{array}$ & no & $\begin{array}{l}\text { available year-round, } \\
\text { possibility to sand- } \\
\text { and dust-bathe }\end{array}$ \\
\hline size of coop & up to 6000 hens & up to 3000 hens \\
\hline feed & $\begin{array}{l}\text { conventional agriculture, } \\
\text { antibiotics allowed }\end{array}$ & $\begin{array}{l}\text { organic agriculture, } \\
\text { no antibiotics allowed }\end{array}$ \\
\hline
\end{tabular}

TABLE 4.-Comparison of Living Conditions

\section{Details Regarding the Living Conditions}

Conventional Option: In the conventional farming environment, each hen has an available average space of 0.17 square meters. This amounts to an area of $41 \mathrm{~cm} \times 41 \mathrm{~cm}$. A pawing area covers approximately one third of the coop. In the remaining two thirds there is a fecal pit with perches above it. Your hen does not have the possibility to go outside. The feed is from conventional agriculture, antibiotics are allowed.

Organic Option: In the organic farming environment, your hen has 4 square meters of grassy outdoor runs as well as a canopied outdoor area with air-conditioning at its disposition, in addition to the area in the coop. Thus, it can walk around on the grass together with its fellows, take a sand bath, pick the ground and experience the fresh air. In addition, it receives organic feed that must satisfy strict standards. Antibiotics may not be fed. The conditions of the "Naturland"-certificate are in many ways stricter than the regulations of the EU ecological certificate: for example, the criteria for feed are stricter, the maximum amount of hens per coop is lower and the animals have the opportunity for free-range activity even in bad weather periods.

The following table gives an overview of the different living conditions and provides you with additional information:

\section{Details Regarding the Payment}

In a few moments, you will be presented with a list of choices. On this list, different amounts of money for choosing the option conventional will be displayed: it starts out with 50 Cents and increases in 50-Cent-steps to 25 Euros. For each of these amounts you can choose between conventional and organic.

Your choice for each of these amounts is important. The computer will randomly select one of the amounts at the end of the experiment. Your choice for this amount of money will be executed with all consequences. Should the computer choose 3 Euros and should you have checked the box for conventional at 3 Euros, the laying hen will be put into the conventional farming environment and you will receive an additional 3 Euros at the end of the experiment. Should the computer choose 22.50 Euros and should you have checked the box for conventional at 22.50 Euros, the laying hen will be put into the conventional 
farming environment and you will receive an additional 22.50 Euros at the end of the experiment. Should the computer choose 15 Euros and should you have checked the box for organic at 15 Euros, the laying hen will be put into the organic farming environment and you will not receive any additional money at the end of the experiment.

\section{Summary}

You are provided with a list of decisions. This list contains different amounts of money for the choice of the conventional option. For each amount of money, you choose between the conventional and the organic option. The computer randomly selects one of these amounts. If you have chosen the conventional option at this amount, you will receive the additional amount of money at the end of the experiment and the hen will be kept in the conventional farming environment for the rest of its life. If you have chosen the organic option at this amount, you will not receive any additional money, and the hen will be kept in an organic farming environment (Naturland) for the rest of its life.

\section{B PRIMING EFFECTS}

Before eliciting subjects' willingness to pay for sustainability, we randomly exposed them to three different texts. ${ }^{21}$ In the control treatment $(\mathrm{C})$, subjects received two texts, one taken from German magazine FOCUS online and one by the renowned physicist and biochemist Francis Crick. These texts dealt with the concept of consciousness and its relevance for medical applications and psychology.

In the second treatment (AFW), subjects were given two texts that argued against the existence of free will. One of the texts was taken from FOCUS online and explained, in a rather summary manner, the basics of the Libet experiment in the 1980 os (Libet, 1985) and a recent contribution from a French group of researchers (Desmurget et al., 2009), claiming that people do not have free will. The other text, again by Francis Crick, argued strongly in favor of a deterministic worldview, in which intentional actions and hence free will are mere illusions.

In the third treatment, we introduced an anti-religion prime (AR), consisting of texts by atheist authors Richard Dawkins and Christopher Hitchens (Dawkins, 2009; Hitchens, 2008). These texts were primarily concerned with outlining the wars and crimes that have been committed in the name of religion, as well as arguing against God's existence.

We expected that evoking anti-free will and anti-religious concepts would alter subjects' behavior on the subsequent animal welfare task towards caring less for the living conditions of a hen.

Contrary to our expectations, priming subjects with concepts of determinism and anti-religious thought did not have an effect on our dependent or independent measures of interest. (See Table 5 for an overview.)

\footnotetext{
${ }^{21}$ All texts are available from the authors upon request.
} 


\begin{tabular}{lc}
\hline Variable & $p$-Value \\
\hline Switching Point & .810 \\
Openness & .809 \\
Agreeableness & .474 \\
Machiavellianism (Tactics) & .991 \\
Machiavellianism (Cynicism) & .527 \\
Feminism Score & .061 \\
Masculinism Score & .647 \\
Age & .067 \\
Gender & .417 \\
Vegetarian or Vegan & .044 \\
Religiosity Dummy & .923 \\
\hline
\end{tabular}

TABle 5.-Kruskal-Wallis Tests for Differences in Switching Points and Personality Characteristics Between Priming Treatments

We therefore decided to retain the observations of all treatments (C, AFW and AR) for analyzing the association of ethical behavior towards humans and animal welfare.

However, note that there are cross-treatment differences in demographic variables like age and gender. This suggests that our sample is somewhat unbalanced across treatments in terms of observables. To address this confound, we present results based on only the control sample in the next section.

\section{ROBUSTNES}

Table 6 presents analyses performed on the control sample only, i.e. those subjects that were given neutral text treatments.

Results are qualitatively similar. The effects of openness and Machiavellianism (Tactics) are larger in magnitude and more precisely estimated. Contrary to the findings in the main text, being a vegetarian or vegan is not predictive for a higher switch point when using the control sample.

These results reinforce the point that demographic criteria seem to have little predictive power for the decision about living conditions of animals. On the other hand, variation in demographics may be larger than that in psychographic criteria, and therefore a larger sample size would have been needed to detect statistically significant effects. 


\begin{tabular}{|c|c|c|c|c|c|c|c|c|}
\hline & \multicolumn{4}{|c|}{ Excluding Multiple Switchers } & \multicolumn{4}{|c|}{ Including Multiple Switchers } \\
\hline & (1) & & (2) & & (3) & & (4) & \\
\hline \multicolumn{9}{|l|}{ model } \\
\hline Openness & $0.957^{* * *}$ & $(0.315)$ & $0.906^{* * *}$ & $(0.331)$ & $0.841^{* * *}$ & $(0.265)$ & $0.773^{* * *}$ & $(0.276)$ \\
\hline Agreeableness & 0.0390 & $(0.485)$ & -0.181 & $(0.516)$ & -0.107 & $(0.362)$ & -0.264 & $(0.381)$ \\
\hline Machiavelli (Tactics) & $-0.980^{* *}$ & $(0.416)$ & $-1.038^{* *}$ & $(0.446)$ & $-0.858^{* *}$ & $(0.361)$ & $-0.914^{* *}$ & $(0.394)$ \\
\hline Machiavelli (Cynicism) & 0.0306 & $(0.613)$ & -0.233 & $(0.614)$ & -0.122 & $(0.463)$ & -0.387 & $(0.467)$ \\
\hline Locus of Control & -0.296 & $(0.277)$ & -0.104 & $(0.275)$ & -0.248 & $(0.234)$ & -0.0821 & $(0.233)$ \\
\hline Feminism Score & 0.0381 & $(0.235)$ & 0.138 & $(0.261)$ & 0.0183 & $(0.200)$ & 0.111 & $(0.216)$ \\
\hline Masculinism Score & 0.0251 & $(0.229)$ & -0.189 & $(0.223)$ & 0.0219 & $(0.201)$ & -0.157 & $(0.192)$ \\
\hline Age & & & 0.457 & $(0.703)$ & & & 0.619 & $(0.565)$ \\
\hline Gender & & & -0.106 & $(4.765)$ & & & 0.883 & $(3.980)$ \\
\hline Vegetarian or Vegan & & & 6.969 & $(7.053)$ & & & 5.053 & $(5.401)$ \\
\hline Religiosity Dummy & & & -4.454 & $(4.740)$ & & & -4.466 & $(3.578)$ \\
\hline Constant & 31.19 & $(39.44)$ & 30.45 & $(42.63)$ & 36.34 & $(30.10)$ & 30.07 & $(33.60)$ \\
\hline Observations & 89 & & 86 & & 101 & & 98 & \\
\hline Pseudo $R^{2}$ & 0.029 & & 0.041 & & 0.026 & & 0.038 & \\
\hline 11 & -220.7 & & -208.8 & & -268.4 & & -256.2 & \\
\hline N_unc & 42 & & 40 & & 54 & & 52 & \\
\hline N_lc & 14 & & 13 & & 14 & & 13 & \\
\hline N_rc & 33 & & 33 & & 33 & & 33 & \\
\hline
\end{tabular}

Standard errors in parentheses

${ }^{*} p<0.10,{ }^{* *} p<0.05,{ }^{* * *} p<0.01$

TABle 6.-Animal Welfare, Personality Traits and Demographics-Control Sample 
Adams, C., Bell, A., Benton, T., Benston, S., Boggs, C., Davis, K., Donovan, J., Gerhardt, C., Johnson, V., Llorente, R., et al. (2011). Critical Theory and Animal Liberation. Rowman \& Littlefield Publishers.

Amemiya, T. (1973). Regression analysis when the dependent variable is truncated normal. Econometrica: Journal of the Econometric Society, pages 9971016.

Bandura, A. (1999). Moral disengagement in the perpetration of inhumanities. Personality and social psychology review, 3(3):193-209.

Bartling, B., Weber, R. A., and Yao, L. (2015). Do markets erode social responsibility? Forthcoming in: Quarterly Journal of Economics.

Bem, S. L. (1981). Bem Sex-Role Inventory: Professional Manual. Consulting Psychologists Press Palo Alto, CA.

Bordalo, P., Gennaioli, N., and Shleifer, A. (2013). Salience and consumer choice. Journal of Political Economy, 121(5):803-843.

Bray, J., Johns, N., and Kilburn, D. (2010). An exploratory study into the factors impeding ethical consumption. Journal of Business Ethics, 98(4):597-608.

Bénabou, R. and Tirole, J. (2011). Identity, morals, and taboos: Beliefs as assets. The Quarterly Journal of Economics, 126(2):805-855.

Carrigan, M. and Attalla, A. (2001). The myth of the ethical consumer-do ethics matter in purchase behaviour? Journal of Consumer Marketing, 18(7):560578 .

Christie, R., Geis, F. L., and Berger, D. (1970). Studies in Machiavellianism. Academic Press New York.

Chung, J. and Trivedi, V. T. (2003). The effect of friendly persuasion and gender on tax compliance behavior. Journal of Business Ethics, 47(2):133-145.

Costa, P. T. and McCrae, R. R. (1992). Neo PI-R professional manual. Odessa, FL: Psychological Assessment Resources, 396:653-65.

Cowe, R. and Williams, S. (2000). Who are the ethical consumers? The Cooperative Bank.

Dawkins, R. (2009). The God Delusion. Random House, New York City.

De Pelsmacker, P., Driesen, L., and Rayp, G. (2005). Do consumers care about ethics? Willingness to pay for fair-trade coffee. Journal of Consumer Affairs, $39(2): 363-385$.

Deckers, T., Armin, F., Kosse, F., and Szech, N. (2016). Homo moralis: Personal characteristics, institutions, and moral decision-making. mimeo. 
Del Barrio, V., Aluja, A., and García, L. F. (2004). Relationship between empathy and the big five personality traits in a sample of spanish adolescents. Social Behavior And Personality, 32(7):677-682.

DePaulo, B. M. and Rosenthal, R. (1979). Telling lies. Journal of Personality and Social Psychology, 37(10):1713.

Descartes, R. (1996). Meditations on first philosophy with selections from the objections and replies (trans. and ed. John Cottingham). Cambridge University Press, Cambridge.

Desmurget, M., Reilly, K. T., Richard, N., Szathmari, A., Mottolese, C., and Sirigu, A. (2009). Movement intention after parietal cortex stimulation in humans. Science, 324(5928):811-813.

DeYoung, C. G., Peterson, J. B., and Higgins, D. M. (2005). Sources of openness/intellect: Cognitive and neuropsychological correlates of the fifth factor of personality. Journal of Personality, 73(4):825-858.

Dohmen, T., Falk, A., Huffman, D., and Sunde, U. (2010). Are risk aversion and impatience related to cognitive ability? The American Economic Review, 100(3):1238-1260.

Eisler, M. C., Lee, M., Tarlton, J. F., Martin, G. B., Beddington, J., Dungait, J., Greathead, H., Liu, J., Mathew, S., and Miller, H. (2014). Agriculture: Steps to sustainable livestock. Nature, 507(7490):32.

Falk, A. and Szech, N. (2013). Morals and markets. Science, 340(6133):707-11.

Falk, A. and Szech, N. (2014). Diffusion of being pivotal and immoral outcomes. mimeo.

Fehr, B., Samsom, D., and Paulhus, D. L. (2013). The construct of machiavellianism: Twenty years later. Advances in Personality Assessment, 9:77.

Felthous, A. R. and Kellert, S. R. (1986). Violence against animals and people: is aggression against living creatures generalized? Journal of the American Academy of Psychiatry and the Law, 14(1):55-69.

Flynn, C. P. (1999). Animal abuse in childhood and later support for interpersonal violence in families. Society and Animals, 7(2):161-172.

Flynn, C. P. (2000). Why family professionals can no longer ignore violence toward animals. Family Relations, 49(1):87-95.

Ford, R. C. and Richardson, W. D. (1994). Ethical decision making: A review of the empirical literature. Journal of Business Ethics, 13(3):205-221.

Francione, G. (1995). Animals, Property \& The Law. Temple University Press.

Geis, F. L. and Moon, T. H. (1981). Machiavellianism and deception. Journal of Personality and Social Psychology, 41(4):766. 
Gennaioli, N. and Shleifer, A. (2010). What comes to mind. The Quarterly Journal of Economics, 125(4):1399-1433.

Gneezy, U., Imas, A., and Madarász, K. (2014). Conscience accounting: Emotion dynamics and social behavior. Management Science, 6o(11):2645-2658.

Gordon, J. S. (1996). The chicken story: A century ago you'd eat steak and lobster when you couldn't afford chicken. American Heritage, 47:52-67.

Graziano, W. G., Habashi, M. M., Sheese, B. E., and Tobin, R. M. (2007). Agreeableness, empathy, and helping: A person $\times$ situation perspective. Journal of Personality and Social Psychology, 93(4):583.

Greiner, B. (2004). An online recruitment system for economic experiments. mimeo.

Gruen, L. (2014). The moral status of animals. In Zalta, E. N., editor, The Stanford Encyclopedia of Philosophy. Fall 2014 edition.

Gullone, E. (2011). Conceptualising animal abuse with an antisocial behaviour framework. Animals, 1(1):144-16o.

Hitchens, C. (2008). God is not great: How religion poisons everything. Random House, New York City.

Kahane, G., Wiech, K., Shackel, N., Farias, M., Savulescu, J., and Tracey, I. (2012). The neural basis of intuitive and counterintuitive moral judgment. Social Cognitive and Affective Neuroscience, 7(4):393-402.

Kant, I. (1981). Lectures on Ethics. Hackett Publishing Company, Cambridge.

Kelemen, L. E., Kushi, L. H., Jacobs, D. R., and Cerhan, J. R. (2005). Associations of dietary protein with disease and mortality in a prospective study of postmenopausal women. American Journal of Epidemiology, 161(3):239-249.

Latané, B. and Nida, S. (1981). Ten years of research on group size and helping. Psychological Bulletin, 89(2):308.

Libet, B. (1985). Unconscious cerebral initiative and the role of conscious will in voluntary action. The Behavioral and Brain Sciences, 8:529-566.

Locke, J. (1996). Some Thoughts Concerning Education: And, of the Conduct of the Understanding. Hackett Publishing Company, Cambridge.

Loe, T. W., Ferrell, L., and Mansfield, P. (200o). A review of empirical studies assessing ethical decision making in business. Journal of Business Ethics, 25(3):185-204.

Lund, D. B. (2000). An empirical examination of marketing professionals' ethical behavior in differing situations. Journal of Business Ethics, 24(4):331342 .

Marshall, B. and Dewe, P. (1997). An investigation of the components of moral intensity. Journal of Business Ethics, 16(5):521-529. 
McCarthy, R. F. and Bennett, R. E. (1985). Statutory protection for farm animals. Pace Environmental Law Review, 3:229.

McCrae, R. R. and Costa, P. T. (1997). Conceptions and correlates of openness to experience. Academic Press, London.

Muris, P., Meesters, C., and Timmermans, A. (2013). Some youths have a gloomy side: Correlates of the dark triad personality traits in non-clinical adolescents. Child Psychiatry \& Human Development, 44(5):658-665.

Nicholls, A. and Lee, N. (2006). Purchase decision-making in fair trade and the ethical purchase 'gap': Is there a fair trade twix? Journal of Strategic Marketing, $14(4): 369-386$.

Olver, J. M. and Mooradian, T. A. (2003). Personality traits and personal values: a conceptual and empirical integration. Personality and Individual Differences, 35(1):109-125.

O'Fallon, M. J. and Butterfield, K. D. (2005). A review of the empirical ethical decision-making literature: 1996-2003. Journal of Business Ethics, 59(4):375413.

Radtke, R. R. (2000). The effects of gender and setting on accountants' ethically sensitive decisions. Journal of Business Ethics, 24(4):299-312.

Ross, W. T. and Robertson, D. C. (2003). A typology of situational factors: Impact on salesperson decision-making about ethical issues. Journal of Business Ethics, 46(3):213-234.

Rothenhäusler, D., Schweizer, N., and Szech, N. (2015). Institutions, shared guilt, and moral transgression.

Sakalaki, M., Richardson, C., and Thépaut, Y. (2007). Machiavellianism and economic opportunism. Journal of Applied Social Psychology, 37(6):1181-119o.

Singer, P. (1995). Animal liberation. Random House, New York City.

Singhapakdi, A. and Vitell, S. J. (1990). Marketing ethics: Factors influencing perceptions of ethical problems and alternatives. Journal of Macromarketing, $10(1): 4-18$.

Singhapakdi, A., Vitell, S. J., Rao, C., and Kurtz, D. L. (1999). Ethics gap: Comparing marketers with consumers on important determinants of ethical decision-making. Journal of Business Ethics, 21(4):317-328.

Sobel, J. (2010). Markets and other-regarding preferences. mimeo.

Straughan, R. D. and Roberts, J. A. (1999). Environmental segmentation alternatives: A look at green consumer behavior in the new millennium. Journal of Consumer Marketing, 16(6):558-575.

Thompson, G. D. (1998). Consumer demand for organic foods: What we know and what we need to know. American Journal of Agricultural Economics, $80(5): 1113-1118$. 
Thompson, K. L. and Gullone, E. (2003). Promotion of empathy and prosocial behaviour in children through humane education. Australian Psychologist, 38(3):175-182.

Tobin, J. (1958). Estimation of relationships for limited dependent variables. Econometrica: Journal of the Econometric Society, pages 24-36.

Van der Zee, K., Thijs, M., and Schakel, L. (2002). The relationship of emotional intelligence with academic intelligence and the big five. European Journal of Personality, 16(2):103-125.

Wilkowski, B. M., Robinson, M. D., and Meier, B. P. (2006). Agreeableness and the prolonged spatial processing of antisocial and prosocial information. Journal of Research in Personality, 40(6):1152-1168.

Wise, S. (2014). Rattling the cage: Toward legal rights for animals. Da Capo Press, Boston. 


\section{Working Paper Series in Economics}

recent issues

No. 103 Konstanze Albrecht, Florentin Krämer and Nora Szech: Animal welfare and human ethics: A personality study, June 2017

No. 102 Jannis Engel and Nora Szech: A little good is good enough: Ethical consumption, cheap excuses, and moral self-licensing, March 2017

No. 101 David Freeman, Erik O. Kimbrough, J. Philipp Reiss: Opportunity cost, inattention and the bidder's curse, February 2017

No. 100 Andranik S. Tangian: Selection of questions for VAAs and the VAA-based elections, January 2017

No. 99 Dominik Rothenhäusler, Nikolaus Schweizer and Nora Szech: Guilt in Voting and Public Good Games, November 2016

No. 98 Eckhardt Bode, Stephan Brunow, Ingrid Ott and Alina Sorgner: Worker personality: Another skill bias beyond education in the digital age, November 2016

No. 97 Clemens Puppe: The single-peaked domain revisited: A simple global characterization, November 2016

No. 96 David Burka, Clemens Puppe, Laszlo Szepesvary and Attila Tasnadi: Neural networks would 'vote' according to Borda's rule, November 2016

No. 95 Vladimir Korzinov and Ivan Savin: Pervasive enough? General purpose technologies as an emergent property, November 2016

No. 94 Francesco D'Acunto, Daniel Hoang and Michael Weber: The effect of unconventional fiscal policy on consumption expenditure, October 2016

No. 93 Andranik S. Tangian: The third vote experiment: VAA-based election to enhance policy representation of the KIT student parliament, September 2016 